\title{
Lessons in Effective Practical Chemistry at Tertiary Level: Case Studies from a Chemistry Outreach Program
}

\author{
D. E. Shallcross ${ }^{1}$, T. G. Harrison ${ }^{1}$, A. J. Shaw ${ }^{1}$, K. L. Shallcross ${ }^{1}$, S. J. Croker $^{1}$ \& N. C. Norman ${ }^{1}$ \\ ${ }^{1}$ School of Chemistry, Bristol University, UK \\ Correspondence: D. E. Shallcross, School of Chemistry, Bristol University, BS8 1TS, UK. E-mail: \\ d.e.shallcross@bris.ac.uk
}

Received: November 20, 2012 Accepted: June 27, 2013 Online Published: September 22, 2013

doi:10.5539/hes.v3n5p1 URL: http://dx.doi.org/10.5539/hes.v3n5p1

\begin{abstract}
Two summer schools focused on practical chemistry, one involving secondary school students and one involving visually impaired adults (i.e., not involving undergraduates) have produced students that appeared to be on the way to achieving the basic criteria set out by Buckley and Kempa (1971) in terms of practical skills. These criteria being that laboratory work should aim to encourage students to gain

- Manipulative skills

- Observational skills

- The ability to interpret experimental data

- The ability to plan experiments.

Extensive pre-laboratory work, blocking of laboratory time to ensure that a series of practicals could be worked through and continuity of the course, where ideas are built upon, were identified as key aspects that contributed to the students development during the summer school. Assessment is often seen as the driver for either surface level or deep level learning, here these summer schools did not have formal assessments but the emphasis was on assessing practical skills rather than assessing a long practical write-up. Follow-up interviews after 2-5 years of the school students showed that the chance to experience University, meet like-minded students and make friends is as strong a motivation as learning new practical skills.
\end{abstract}

Keywords: practical chemistry, pre-laboratory work, practical assessment, design of practical

\section{Introduction}

In recent years the spotlight has been shone on the practical elements of teaching chemistry at tertiary level. Bennett and O'Neale (1998) suggest that many undergraduate chemists, in the UK at least, never return to a laboratory once they graduate. Therefore, the notion that the prime purpose of practical chemistry at tertiary level is to train a professional chemist is somewhat inappropriate. However, in a survey of recent graduates it has been noted they value a laboratory-based training regardless of whether they carry on in a Chemistry (Science) based career (Hanson and Overton, 2010). Here, the survey by Hanson and Overton of former students, noted that items deemed useful or very useful included; analytical techniques (70\%), safe handling of chemical materials (75\%), manipulative practical skills (71\%), planning and design of experiments (63\%), interpretation of experimental data (76\%), report writing skills $(81 \%)$, problem solving skills $(92 \%)$, team-working skills $(87 \%)$ and time management and organizational skills (94\%). Therefore it would seem that practical work has an important role in supporting a range of skills valued by graduates, irrespective of future career.

Bennett and Neale (1998) also assert that stipulating a minimum number of hours that must be spent in the laboratory can lead to the dangerous assumption that competence follows automatically from experience, without the need for assessment of skills.

Johnstone and Al-Shuaili (2001) provide a comprehensive review of the whole topic of learning in the laboratory and remind us of the pioneering work of Kerr (1963), who surveyed teachers over a two-year period in secondary schools in England and Wales and arrived at the following ten aims of practical work; 
- To encourage accurate observations and careful recording.

- To promote simple, commonsense, scientific methods of thought.

- To develop manipulative skills.

- To give training in problem solving.

- To fit the requirements of practical exams.

- To elucidate theoretical work so as to aid comprehension.

- To verify facts and principles already taught.

- To be an integral part of the process of finding facts by investigating and arriving at principles.

- To arouse and maintain interest in the subject.

- To make phenomena more real through actual experience.

In recent years 'To fulfill the requirements of external examination coursework' in UK secondary-schools could be added.

Johnstone and Al-Shuaili (2001) go on to note that many researchers of tertiary practical chemistry have broadly agreed with the work of Kerr (1963) that was centred on secondary practical science and suggest that a more condensed list derived from the work of Buckley and Kempa (1971) summarises the core of what is needed for practical work at tertiary level. Buckley and Kempa state that laboratory work should aim to encourage students to gain;

- Manipulative skills

- Observational skills

- The ability to interpret experimental data

- The ability to plan experiments.

To this list could be added an understanding of error analysis. With these ideas in mind we report two case studies from the Bristol ChemLabS (Shallcross et al., 2013) Outreach Program where these desired outcomes were being achieved by students. In both case studies we attempt to tease out the reasons why these practical encounters seemed successful and how this can inform the way we conduct practical chemistry at tertiary level.

\section{Background to the Case Studies}

Case Study 1 involves a two-week summer school for 20 UK school students (9 female, 11 male) in Year 10-11 (14-16 years of age) who were all members of the National Association for Gifted and Talented Youth (NAGTY; e.g., Hartas et al., 2008). Therefore these students were in the top 5\% of their cohort in Science on a national basis. The summer school was on the theme of the Chemistry of the Pharmacy. The second case study was a week-long summer school on the theme of structure and bonding (Chemistry gets Physical) for 15 visually impaired adults aged from 28 to 84 years. Most of these adults had no sight at all, but some did have partial sight and were able to read large print text. All visually impaired students were accompanied by sighted guides, who, in the main, did not have a science background. Some visually impaired students were also accompanied by guide dogs. In addition to the two course leaders, there were three postgraduate demonstrators available at all times and in laboratory sessions an additional postgraduate demonstrator and technician.

\section{Case Study 1: NAGTY Summer School}

The Summer School was led by an academic and a school teacher, together with two postgraduate demonstrators and two technicians who worked with the students for the whole two weeks. The postgraduate demonstrators were extremely experienced having worked in the undergraduate teaching laboratories for nearly three years. They had worked through all the laboratory scripts and practicals that were to be carried out several times before the start of the Summer School. Therefore, there was six staff available for 10 pairs of students throughout the practical experience. Each day started at 9.30 am and finished at $5 \mathrm{pm}$, with an ever decreasing lunch break (see later).

The first day was taken up with introductions, an overview of the two week course including a safety talk, a tour of the department, some practical competitions used as ice breakers (closest to a minute using the iodine clock reaction (Sattsangi, 2011), determination of the sugar content in soft drinks and the determination of $\mathrm{Fe}^{2+}$ in iron tablets), a short talk on UCAS applications (the UK's university applications process) and a plenary session, where prizes were awarded and a debrief on each of the practicals. At the end of day one, even though the 
students had only been in the laboratory for half of that day, they were all very tired, unused to standing whilst working at a bench for that length of time. Given the emphasis on practical chemistry in the program, we feared at this point that the students would not last the course, but, the group was working well together.

For the next three days the summer school followed a similar pattern where the first twenty to thirty minutes was spent giving an overview of the day's synthesis (aspirin and antifebrin) or extraction (caffeine), pointing out the importance of the compound, safety precautions, the new techniques to be used and a demonstration of how the apparatus should be constructed and used. The students would then carry out practical work for about 1-1.5 hours before a break for refreshments where a further update on the practical was given as required. After the break the students would work on until lunch (a further 1-1.5 hours). Depending on the length of the practical a further session after lunch was used to finish off the work. Having synthesized or extracted a new material each day, the students were then introduced to a new method of characterization each afternoon (infra red spectroscopy, thin layer chromatography and mass spectrometry) and were able to run their own samples and analyze, with help, the results. A plenary session in the late afternoon where results were discussed was followed on two of the days by talks from academics within Chemistry and Pharmacology, on 'How aspirin works in the body' and 'Drugs on the brain' that looked at latest research into cures for Alzheimer's disease and other ailments. On the fourth day the students were given time to prepare a talk on any aspect of the summer school covered and given a tutorial on using ChemDraw (chemical structures drawing package).

On day five the students were given some unknown compounds to identify in the morning session and in addition to the standard tests they also had the chance to use the new techniques they had been introduced to. Following a debrief in the afternoon and a look ahead to the following week the students had one further session to refine their presentations before giving them to an audience of academics. These included the postgraduate chemists that had been working with the group. The standard of presentation was very high and the depth of understanding was evident from the clarity and quality of answers given to questions from the audience.

In the original plan for all the summer schools running, a lunch break of 1 hour and fifteen minutes was set aside, after day three the students on this particular strand of the summer school asked if they could shorten this time to 30 minutes (a compromise of a 45 minute lunch break was reached) because they were enjoying the laboratory experience so much.

On days 6 and 7 there were 'field trips' one to a perfumer and another to a chemical engineering department, where students spent the day carrying out a circus of six practical challenges. By day 8 there was a very clear change in the psyche of the group. In the 'pre-lab' session it was clear that many students had read the practical for that day in some depth and we were asked many interesting and insightful questions about that day's practical; steam distillation and a clove oil experiment. During that day a couple of students asked if they could extend the practical, having read around the experiment and were allowed to do so. The last two days of the summer school were an amazing experience, where students not only completed the practicals we had designed but in addition they carried out their own analyses unprompted. These analyses included running their own i.r. spectra, melting points etc, having mastered the techniques earlier, as they felt appropriate. Several had begun to design a follow up experiment on their own, again unprompted. One group in particular had extended the work to look at the kinetics of the reaction of one of the synthesized molecules with a co-reactant. Did they achieve the objectives set out by Buckley and Kempa (1971) that laboratory work should aim to encourage students to gain;

- Manipulative skills

- Observational skills

- The ability to interpret experimental data

- The ability to plan experiments.

The transformation in the students' manipulative skills (judged by the reduction in time taken to complete the same skill element as the summer school progressed and the more complex tasks undertaken and the dramatic reduction in broken glassware in week 2) and observational skills (judged through discussion with tutors and demonstrators within the laboratory and during plenaries and pre-laboratory sessions) were clear. Through the plenaries and pre-laboratory sessions we were able to assess their abilities to interpret the experimental data they had collected. Here it was also very clear that significant progression had taken place over the two weeks. Students were able to derive much more information from the data they were generating and because they were prepared for the laboratory sessions they were able to notice data that were erroneous or suspect. Over the course of the two weeks their attitude towards suspect data changed, at first they would discover this at the end of the practical when they had worked up their data. During the course of the two weeks they began to work up data as 
they went along. By the end of the two weeks if they suspected a problem they would stop and repeat measurements until they were convinced that the measurement was correct (statistically) and then assess whether that whole element required repetition. Although the desire to 'get it right' was evident, the students were just as interested in understanding why that element of the practical had not worked and what they could do to put it right. Since they were now working at a much quicker pace than at the start of the summer school, they had time to carry out extra analyses. There was a session at the end of week 2 where we has planned a 'plan your own' practical, but these students were already planning and adding to the practicals before this. Therefore, we conclude that the answer to the original question would be yes, the students ably demonstrated their improved manipulative and observational skills, their ability to interpret and plan experiments. In addition, the quality of their presentations during the plenary sessions and at other times showed that they had been able to interpret the results from their analytical characterizations and where these showed that there may have been impurities in the product, they went as far as possible in identifying those and thinking about how these could be eliminated. Apart from the identification of the unknown compounds we did not expect the students to plan and run their own experiments, but they were not only capable of doing this but clearly relished this opportunity.

We received many very positive comments from the formal and informal feedback from the students, but this one was the most telling;

'For both of us, the course has been a life changing experience that we will never forget. We found the standard of teaching exceptional... because they treated us as adults and tried their best to make the course as good as it could be.

Throughout the course we never ceased to be amazed at the facilities made available to us. The chemistry summer school was one of the best experiences of our lives (not exaggerating!) and will be remembered for years to come.'

\section{Thoughts on Case Study 1}

It is well known that the method of assessment will play a major role in determining whether the students' approach involves deep level learning or surface level learning (Marton, 1975; Pask, 1976; Laurilland, 1979; Ramsden and Entwistle, 1981; Gibbs, 1992; Glasner, 1999). In this case study the assessments, while challenging, did not count towards an important qualification. One could argue that the students were free to engage in deep level learning. There was no pressure on these students to prepare for the assessment. Noting that these were bright students, the counter question could be posed, given that the course didn't count for anything why did they all adopt a deep level learning approach and achieve a very high level of practical and investigative skill in such a short space of time? For these bright students, self-assessment would also be a likely facet that would have contributed to their readiness to prepare for example. We have identified some elements of the course that we believe could be part of the reason.

\subsection{Pre-Laboratory Work}

Pre-laboratory work has been shown to have a positive impact on the learning outcomes of students (e.g., Nicholls, 1999; Brattan et al, 1999). As the summer school progressed, it was clear that students had read the scripts for the next day and were coming to the pre-laboratory sessions with questions and comments. There is little doubt that quality time invested in pre-laboratory work is time well spent from case study 1. Nicholls (1999) describes the successful use of pre-laboratory software that students must complete (including a safety test) that has improved the practical experience. With the opening of the refurbished laboratories at Bristol ChemLabS in 2007 undergraduate students now have a dynamic laboratory manual (DLM), i.e., one that is e-enabled (Harrison and Shallcross, 2008; Harrison et al., 2009; Shallcross et al., 2013). The DLM contains virtual experiments that the student can use to simulate each practical exercise they will be doing, some video clips (see for example McKelvy, 2000) to show the various stages of the experiment, safety information, links to course notes where appropriate and also some formative assessment questions. Each student is expected to have completed the safety assessment and the formative assessment before entering the laboratory, but also attends a short pre-laboratory session where the experiment will be discussed. Data collected since 2008 suggest that such a method goes some way to enthuse the students and for them to be observing more than just what is suggested in the practical script. They have found the virtual experiments very useful and that it has helped with their understanding of the practical investigation. Feedback from the two cohorts of students who experienced laboratories before and after the refurbishment and introduction of the DLM and pre-laboratories demonstrate very clearly the improved situation. Before the change the students dreaded laboratories, where they felt overawed by the experiments. They did not understand the written descriptions and often struggled with the practical. On many occasions they really didn't understand what they were doing and felt that they were 
following a recipe. Only when they completed the practical and spent a lot of time collating, analyzing and writing it up did they finally work out what was going on. If there had been a problem, it was often at this time that it was discovered and therefore it was too late to rectify. Post the change in laboratory set up, the situation is very different, students are keen to be in the laboratories, they have much more confidence and understanding about the work in hand. The role of well trained and motivated demonstrators should not be overlooked and certainly the summer school case study showed the value of such people. The DLM, in addition to the training already given to demonstrators, has lead to an improved experience for the demonstrator and student.

\subsection{Time Spent in the Laboratory}

At the start of this paper the assertion was made (Bennett and Neale, 1998) that the actual time spent in the laboratory is not necessarily a good indicator of competence. However, the very fact that this was a two-week summer school alerted us to the fact that we often set aside time for undergraduate laboratories because of difficult timetabling issues and not because it is the most appropriate slot of time. There was ample time to complete the main experiment of the day and time to go on with an analysis of the product or further experiments. Indeed, the products obtained from days 2-4 of the summer school were used later on and there was a deliberate intention to have recurring themes and synergies between experiments. The students commented that the program as a whole as well as on a day-to-day basis made sense and followed several themes. Bennett and O'Neale (1998) recommendation for skills to progressively develop was achieved in this summer school and those skills were refined and built upon as the course progressed. Bennett and O'Neale (1998) also allude to the fact that continuity is often lacking in undergraduate experimental programs. It may well be that sometimes 2 weeks needs to be blocked off for students to progress through a set of experiments and to be able to immerse themselves in the laboratory experience rather than a day here and an afternoon there. It also allows time for students to design their own subsequent experiments, something that is most desirable (Bennett and O'Neale, 1998; Johnstone and Al-Shuaili, 2001). This summer school has shown us the value of an extended period in the laboratory, not least because students did start to design their own practicals and develop a suite of skills. In concert with several other factors that have emerged as the Bristol ChemLabS project has progressed, an intensive two-week period of practicals has been introduced into the undergraduate program. This intensive period is run at the end of the academic year, after summer examinations and before the end of term, avoiding timetabling clashes and during which students learn core practical skills that are required for the following year. A series of cohorts through this have commented in each case that it was initially viewed very unfavourably, with students reluctant to return to the department after examinations. However, as the course progressed the students realized that there were no long write-ups, just proforma style write-ups to complete and that the emphasis was on attaining practical skills. They all reported that at this point they began to enjoy it and at the end of the course were very positive (a more detailed description of this experience will be reported in a future publication). The students' progress through the two week intensive mirrored that of the summer school students. Following a slow start the students began to enjoy the experience and to understand what it was trying to achieve. Whilst maintaining standards, in week 2 in particular, students were completing laboratories much earlier and were able to move onto extension activities such as spectroscopic analysis or kinetic studies. They enjoyed the continuity and at the end appreciated having a significant block of time just dedicated to practical work.

\subsection{Experimental Design}

Experimental design has already been commented upon in the previous section, and is certainly something we tried to introduce during the summer school during the morning session where students were identifying an unknown. It turned out that the students naturally augmented the practicals, bringing new knowledge and techniques they had learned earlier on to the fore. Clearly the summer school was the focus of attention and when these new shoots of creativity emerged they were intensively cultivated by staff. How could we translate this into a regular practical slot for undergraduates, where resources are far more stretched? One answer is of course to combine practicals so that students might be asked to design and carry out a synthesis and then be asked to determine some physical properties of the product. Some of these elements are incorporated in the new laboratory program (Shallcross et al., 2013). It is worth noting that secondary school science course coursework for 14-16 year olds has required students to design experiments, observe and record data, analyse (interpret) data and to evaluate errors. Such requirements still exist at AS/A2 (post-16 in the UK) level. Therefore students entering UK universities should have these skills, as this summer school showed. Most undergraduate practical courses in Years 1 and 2 do not build on this.

\subsection{Assessment}

The student's results were collected using a proforma sheet, such as masses used, etc. but there was no long 
write-up of these experiments. The students ably demonstrated that they had mastered the practical skills being taught (see previous sections) but also knew why they were doing the experiment and the relevance of each step (through discussion with tutors and demonstrators during the practical, during plenaries and pre-laboratory sessions). There were prizes for the purest compound etc, but the prizes were too trivial to explain the high degree of motivation. It is often the case that long practical write-ups are of little value to the student in terms of cognition, where laboratory scripts may be leaned on heavily in their report, and where marking the script does not afford the teacher the possibility to truly assess practical skill. The Bristol ChemLabS Laboratory Teaching Committee has set in place the proforma style of write-up (with just a handful of longer write-ups being required during the year, with the latter being assessed on the ability to write up experiments and not to attempt to mark practical skills). In addition they have placed more emphasis on practical skills by assessing students using a mini viva towards the end of the practical. The outcome of this will also be reported in a future publication. Therefore, a balance has been struck between developing writing and reporting skills (Hanson and Overton, 2012) and developing practical skills.

\section{Case Study 2: Visually Impaired Summer School}

The Visually Impaired Persons (VIP) summer school on the theme of structure and bonding ran for one week, with the practical elements interspersed with talks and workshops. Materials associated with the course were sent out in advance and audio tape recordings as well as raised diagrams and Braille written notes were available. Interestingly, many students do not read Braille, having lost their sight at some point; usually it is those who have never had sight that may read Braille. The sighted guides were essential in all sessions, particularly those in the laboratory themselves, to orientate the student and talk them through their surroundings. This did prove a problem and took time to do because many guides were not scientists and needed to refer to the postgraduates and tutors for clarification. Noise is of course a problem, and much time was invested at the beginning to reduce extraneous noise so that the students could hear as clearly as possible and communicate with the tutors and each other. Initially, it was frustrating for all, setting up but once done successfully this element speeded up. The students were very patient and appreciated that the set up time was a problem. Classroom sessions where practicals were run were more successful. Here students were much more familiar with surroundings and the smaller space made noise management much easier. It was also essential that multiple models or practical kits were available, preferably one between two or one each, as explanations were impossible if students had to wait to receive the model from other students. The students themselves made it clear that we were to use everyday language and not to worry about using phrases such as 'As you can see'. This helped enormously as there was a considerable amount of trepidation about offending these students.

The first set of talks introduced the idea of the atom and its structure and how the idea of electron shells led onto ideas about bonding. Considerable use of molecular modelling kits was used to describe the structure of water, salt, silica and other common compounds. Further talks took up these themes and discussed solids such as diamond and graphite, how to make ice cream, modern materials and in the evening there were a series of talks on subjects aligned to the course such as perfumes. Students carried out experiments to make a chocolate mixture that melted in the mouth and not in the hand, investigated soft solids such as silly putty and slime and electrochemistry experiments to assess electrode potentials. At the end of every day and at the start of the new day there were sessions to discuss the results from that day and a look forward to the experiments and talks to come from the following day.

\section{Thoughts on Case Study 2}

\subsection{Peer Assisted Learning}

One of the most fascinating aspects of working with this particular group was that they talked with each other and discussed not only with their sighted guide but also their neighbours what they were learning. For example, when discussing the structure of silica, each student made their own $\mathrm{SiO}_{2}$ unit and without prompting they linked it with their neighbours' units to start to build a macro-structure. The students then inspected the structure by touch and each contributed orally to an amazing exploration of this common compound. The power of peer assisted learning was made very apparent, although there is a balance to be struck between class discussion that aids cognition and class discussion that is simply banter. The students learned far more from each other's exploration than they would have done if someone had forced them to sit and listen to some polished exposition on the subject.

\subsection{Fun Practicals}

It goes without saying that Pre-lab work was essential. A lot of preparation and orientation of the students was required, but, this time was well spent. Many students showed a keen insight into the experiments they were 
performing and were genuinely having fun. The use of talking instruments such as talking timers, mass balances and colour recognition devices was new to most of the demonstrating team and required some practice, but the students were able to use them very well. The students were genuinely having fun as well as learning; the practicals were designed to be that way. One student remarked that,' Things I never understood at O'level [an old English schools' qualification (prior to the mid 1980s) taken at 16 years of age by the top $20 \%$ academically] have finally made sense.' Another student commented that 'Having an opportunity to test the theories out in practice was great.' Can we have more fun practicals in an undergraduate course and still learn?

\subsection{Impact on Teachers}

It is fair to say that most academics who took part in the summer school were terrified of saying something that was perceived as being out of place or deemed inappropriate for this cohort, e.g., the dreaded phrase 'We can see that...' Indeed all colleagues agreed that this had been the hardest and yet most rewarding teaching experience they had encountered in a long time. Being forced to abandon a totally visual presentation was extremely beneficial to all teachers. First, teachers were prompted to go back to the subject matter and reformulate it for the new audience. This meant rediscovering tactile learning in many cases and moreover engaging senses other than visual. Several teachers have gone back to courses they have taught for many years and re-evaluated the way they are taught. Second, all teachers commented how good this particular group were at peer assisted learning and noted possibly for the first time the power of stepping back and letting the learners pass on knowledge to each other. Third, the experience re-emphasized how valuable preparation for the laboratory is. The pre-lab sessions had to be clear and well presented and just as in Case Study 1 the students had done their preparation and were ready to engage in the practical work from the start of the session.

Comparing the two case studies, there were far more support staff in the VIP summer school. Elements of work took much longer to achieve with the VIP learners, as much as three to four times as long and the equipment used was much simpler in the VIP summer school, as it either had to talk, or make a noise or have some other sensory (touch, taste or smell) response for it to be worth using. The challenges were very different and required very different skill sets.

\subsection{Follow-Up Interviews 2-5 Years Later}

Follow-up interviews 2-5 years after the summer schools were conducted. Sixty students attended NAGTY summer schools over the period 2005-2007 and over the period 2009-2010 it was possible to contact eighteen of these students to conduct interviews and complete questionnaires. The spread of responding students was quite even from the three summer schools, 2005 (7 students), 2006 (6 students), 2007 (5 students) and of these 6 were now undergraduates, 11 were taking A levels (UK post-16 qualifications) and 1 was taking GCSEs (current UK qualifications at 16). Sixteen out of 17 who had or were taking A levels had taken Chemistry. The one student who did not take Chemistry at post-16 level wrote;

'Despite the very enjoyable educational experience, the summer school did demonstrate to me that chemistry was not the subject, or career option I wanted to pursue, and so allowed me to consider other options in greater detail at an earlier stage.'

The most popular non chemistry A levels were Physics (14), Mathematics (13), Biology (9) and Further Mathematics (5), emphasizing the bias towards Science and Mathematics choices. When asked why they had attended the summer school the most frequent answers were to increase knowledge, learn new things, and to meet new people. A particular response that reflected many was;

'I was fairly certain that I wanted to study chemistry at university but had been bored at GCSE and my external reading had further interested me so I wanted a chance to go further and do things I hadn't/wouldn't at school.'

The respondents' beliefs about the benefits they gained from attending the summer school were varied. Different students benefit in ways they were not expecting. The most cited benefit was making friends and meeting new people. This corresponds to a common reason for originally attending.

The second most cited benefit was that of increased confidence, in themselves, or their abilities. This is interesting as it was not directly cited as a reason to attend by any of the respondents. It is possible that the students didn't consider this might be a benefit beforehand, or that it had a much bigger effect on their confidence than anticipated.

Other benefits noted included improved skills and knowledge, and these gains having a direct impact in later studies. The variety of benefits suggests that a summer school experience is important in a number of different ways for different students. A typical comment was: 
'I do feel I developed a lot as a person, before then I had not been away on my own for an extended period. I met lots of interesting, like-minded people who I am regularly in contact with and meet occasionally. My knowledge in the areas increased substantially, and because I had chosen to do it, I was motivated meaning that I worked harder and learnt more than I would otherwise. The things I learned proved valuable when studying related areas at a higher level.'

There was a varied response to the question of impact of the summer school on future choices. Considering the impact on further study, the most common response was that it had a little impact, but responses were spread. The picture is similar for impact on future career, although more students responded that the summer school had very little or no impact. This again could be related to the age of respondents at the time of attending, as it may be that they were more focused on study decisions rather than career decisions further in the future. It is clear from A level data that the majority pursued science and mathematics and therefore it is likely that they had already made decisions about future courses.

'I think the most valuable benefit was the increase in confidence in practical work as I had really struggled with that before.'

'The chance to meet people my age who I connected with on an intellectual level and to experience a taste of university life.'

$\ldots$ and an interesting outcome:

'A beautiful girlfriend, though that's probably not relevant... aside from that, a privileged insight into university facilities \& research'.

Finally, when asked whether they would recommend the summer school there was unanimous agreement with the following interesting quotes:

'Having parents who have not been to university, I did not appreciate what University entails and selection procedures until I attended.'

'The chance to do some degree-level chemistry experiments at the age of 14-16 years old should not be passed over. The summer school provides a fantastic opportunity to meet like-minded people from all over the country and, in my case, form what I feel will be lasting friendships and a relationship. The tutors who delivered the course... were delightful and so informative and it was also useful to be able to talk to current university students.'

'Chance to learn not just for exams.'

\section{Summary and Conclusions}

Through the Bristol ChemLabS Outreach Program, two summer schools have produced students that were well on the way to achieving the basic criteria set out by Buckley and Kempa (1971). Reasons for this success are extensive pre-laboratory work, blocking of laboratory time to ensure that a series of practicals can be worked through and continuity of the course, where ideas are built upon. Assessment is often seen as the driver for either surface level or deep level learning, here these summer schools did not have formal assessments but the emphasis was on assessing practical skills rather than assessing a long practical write-up and on having fun. Many of these successful elements have been incorporated in the Bristol ChemLabS teaching laboratories' (Shallcross et al, 2013) and their impact will be reported in future work.

It should be noted that there are many organizations running summer schools in science for school students, e.g., Salters Institute (2013) and for adults, e.g., Open University (2013), but very few engaging with visually impaired adults. The feedback from students after some years shows that the cohort attending is not typical (though we knew that). They had already decided to pursue a science pathway and were highly motivated and determined. They did enjoy the fact that there was no pressure, no tests and no exams. An interesting and recurring feature in other shorter summer schools we have run since for school students is that the social and interactive aspects and just experiencing university ahead of time was as important and useful as anything else, e.g., practical skills (Shaw et al., 2010a; 2010b).

\section{Acknowledgments}

We thank Dr Vince Smith and Claire Wickham for their help with the Visually Impaired Persons Summer School and the European Social Fund for financial support. Dudley Shallcross thanks the HEA for a National Teaching Fellowship and we gratefully acknowledge HEFCE for funding through the CETL award. We also thank an anonymous referee for extremely helpful and supportive comments that improved this manuscript considerably. 


\section{References}

Bennett, S. W., \& O'Neal, K. (1998). Skills Development and Practical Work in Chemistry. University Chemistry Education, 2, 58-62.

Brattan, D., Mason, D., \& Rest, A. J. (1999). Changing the nature of Physical Chemistry practical work. University Chemistry Education, 3, 59-63.

Buckley, J. G., \& Kempa, R. F. (1971). Practical Work in Sixth Form Chemistry. School Science Review, 53, 24-36.

Gibbs, G. (1992). Improving the quality of student learning. Bristol: Technical and Education Services Ltd.

Glasner, A. (1999, March 26). Hurdlers who stay the course. THES, 42(2). London: Times Newspapers.

Hanson, S., \& Overton, T. L. (2010). Skills required by new chemistry graduates and their development in degree programmes, Higher Education Academy, ISBN 978-1-903815-29-8.

Harrison, T. G., \& Shallcross, D. E. (2008). A chemistry dynamic laboratory manual for schools. Chemistry in Action, 86, 20-22.

Harrison, T. G., Shallcross, D. E., Heslop, W. J., Eastman, J. R., \& Baldwin, A. (2009). Transferring Best Practice from Undergraduate Practical Teaching to Secondary Schools: The Dynamic Laboratory Manual. Acta Didactica Napocensia, 2(1), 1-8.

Hartas, D., Lindsay, G., \& Muijs, D. (2008). Identifying and selecting able students for the NAGTY summer school: Emerging issues and future considerations. High Ability Studies, 19, 5-18. http://dx.doi.org/10.1080/13598130801980265

Johnstone, A. H., \& Al-Shuaili, A. (2001). Learning in the laboratory; some thoughts from the literature. University Chemistry Education, 5, 42-51.

Kerr, J. F. (1963). Practical work in school science: An account of an inquiry into the nature and purpose of practical work in school science teaching in England and Wales. Leicester: Leicester University Press.

Laurilland, D. (1979). The process of student learning. Higher Education, 8, 395-409. http://dx.doi.org/10.1007/BF01680527

Marton, F. (1975). How students learn. In N. J. Entwistle, \& D. Hounsell (Eds.), How students learn. Lancaster: University of Lancaster.

McKelvy, G. M. (2000). Preparing for the Chemistry Laboratory: An internet presentation and assessment tool. University Chemistry Education, 4, 46-49.

Nicholls, B. S. (1999). Pre-laboratory support using dedicated software. University Chemistry Education, 3, 22-27.

Open University. (2013). Retrieved June 25, 2013, from http://www.open.ac.uk

Pask, G. (1976). Styles and strategies of learning. British Journal of Educational Psychology, 46, 12-25. http://dx.doi.org/10.1111/j.2044-8279.1976.tb02981.x

Ramsden, P., \& Entwistle, N. J. (1981). Effects of academic departments on students' approaches to studying. $\begin{array}{lllll}\text { British Journal of Educational } & \text { Psychology, }\end{array}$ http://dx.doi.org/10.1111/j.2044-8279.1981.tb02493.x

Salter's Institute. (2013). Retrieved June 25, 2013, from http://saltersinstitute.co.uk/camps/camp-news/

Sattsangi, P. D. (2011). A microscale approach to chemical kinetics in the general chemistry laboratory: The Potassium Iodide Hydrogen Peroxide Iodine-Clock reaction. J. Chem., Educ., 88, 184-188. http://dx.doi.org/10.1021/ed100140w

Shallcross, D. E., Harrison, T. G., Obey, T. M., Croker, S. J., \& Norman, N. C. (2013). Outreach within the Bristol ChemLabS CETL (Centre for Excellence in Teaching and Learning). Higher Education Studies, 3, 39-49. http://dx.doi.org/10.5539/hes.v3n1p39

Shaw, A. J., Harrison, T. G., Croker, S. J., Medley, M., Sellou, L., Shallcross, K. L., Williams, S. J., \& Shallcross, D. E. (2010a). University-School partnerships: Polymer Chemistry days run at a University for 14-15 year olds and their impact on attitudes to Science. Acta Didactica Napocensia, 3(1), 19-26.

Shaw, A. J., Harrison, T. G., Croker, S. J., Medley, M., Sellou, L., Shallcross, K. L., Williams, S. J., \& Shallcross, D. E. (2010a). University-School partnerships: On the impact on students of Summer Schools (for school 
students aged 17-18) run by Bristol ChemLabS. Acta Didactica Napocensia, 3(4), 35-48.

\section{Copyrights}

Copyright for this article is retained by the author(s), with first publication rights granted to the journal.

This is an open-access article distributed under the terms and conditions of the Creative Commons Attribution license (http://creativecommons.org/licenses/by/3.0/). 